\title{
Estimation of speciated and total mercury dry deposition at monitoring locations in eastern and central North America
}

\author{
L. Zhang ${ }^{1}$, P. Blanchard ${ }^{1}$, D. A. Gay ${ }^{2}$, E. M. Prestbo ${ }^{3}$, M. R.Risch ${ }^{4}$, D. Johnson ${ }^{5}$, J. Narayan ${ }^{1}$, R. Zsolway ${ }^{6}$, \\ T. M. Holsen ${ }^{7}$, E. K. Miller ${ }^{8}$, M. S. Castro ${ }^{9}$, J. A.Graydon ${ }^{10}$, V. L. St. Louis ${ }^{10}$, and J. Dalziel ${ }^{11}$ \\ ${ }^{1}$ Air Quality Research Division, Science and Technology Branch, Environment Canada, Toronto, ON, Canada \\ ${ }^{2}$ Illinois State Water Survey, Prairie Research Institute, University of Illinois, Champaign, IL, USA \\ ${ }^{3}$ Tekran Instruments Corporation, Toronto, ON, Canada \\ ${ }^{4}$ US Geological Survey, Indianapolis, IN, USA \\ ${ }^{5}$ Convex Logic, Gloucester, ON, Canada \\ ${ }^{6}$ New Jersey Department of Environmental Protection, NJ, USA \\ ${ }^{7}$ Department of Civil and Environmental Engineering, Clarkson University, Potsdam, NY, USA \\ ${ }^{8}$ Ecosystems Research Group Ltd, Norwich, VT, USA \\ ${ }^{9}$ University of Maryland Center for Environmental Science, Frostburg, MD, USA \\ ${ }^{10}$ Department of Biological Sciences, University of Alberta, Edmonton, AB, Canada \\ ${ }^{11}$ Air Quality Science Section, Meteorological Service of Canada, Environment Canada, Dartmouth, NS, Canada
}

Correspondence to: L. Zhang (leiming.zhang@ec.gc.ca)

Received: 16 January 2012 - Published in Atmos. Chem. Phys. Discuss.: 27 January 2012

Revised: 24 April 2012 - Accepted: 25 April 2012 - Published: 15 May 2012

\begin{abstract}
Dry deposition of speciated mercury, i.e., gaseous oxidized mercury (GOM), particulate-bound mercury (PBM), and gaseous elemental mercury (GEM), was estimated for the year 2008-2009 at 19 monitoring locations in eastern and central North America. Dry deposition estimates were obtained by combining monitored two- to four-hourly speciated ambient concentrations with modeled hourly dry deposition velocities $\left(V_{\mathrm{d}}\right)$ calculated using forecasted meteorology. Annual dry deposition of GOM+PBM was estimated to be in the range of 0.4 to $8.1 \mu \mathrm{g} \mathrm{m}^{-2}$ at these locations with GOM deposition being mostly five to ten times higher than PBM deposition, due to their different modeled $V_{\mathrm{d}}$ values. Net annual GEM dry deposition was estimated to be in the range of 5 to $26 \mu \mathrm{g} \mathrm{m}^{-2}$ at 18 sites and $33 \mu \mathrm{g} \mathrm{m} \mathrm{m}^{-2}$ at one site. The estimated dry deposition agrees very well with limited surrogate-surface dry deposition measurements of GOM and PBM, and also agrees with litterfall mercury measurements conducted at multiple locations in eastern and central North America. This study suggests that GEM contributes much more than GOM+PBM to the total dry deposition at the majority of the sites considered here; the only exception is at locations close to significant point sources where GEM and
\end{abstract}

GOM+PBM contribute equally to the total dry deposition. The relative magnitude of the speciated dry deposition and their good comparisons with litterfall deposition suggest that mercury in litterfall originates primarily from GEM, which is consistent with the limited number of previous field studies. The study also supports previous analyses suggesting that total dry deposition of mercury is equal to, if not more important than, wet deposition of mercury on a regional scale in eastern North America.

\section{Introduction}

Atmospheric mercury $(\mathrm{Hg})$ dry and wet deposition need to be quantified to reduce large gaps existing in global $\mathrm{Hg}$ mass balance estimates, assess $\mathrm{Hg}$ effects on various ecosystems, and attribute sources of deposited $\mathrm{Hg}$ for $\mathrm{Hg}$ emission controls (Mason and Sheu, 2002; Mason et al., 2005; Lindberg et al., 2007; Selin et al., 2007). The Mercury Deposition Network (MDN) of the National Atmospheric Deposition Program (NADP) in the USA and Canada was established more than a decade ago to measure the wet deposition of $\mathrm{Hg}$ in 
precipitation (Vanarsdale et al., 2005; Prestbo and Gay, 2009; Risch et al., 2012b). More recently, the Atmospheric Mercury Network (AMNet) of NADP was also established to monitor speciated concentrations of atmospheric $\mathrm{Hg}$ for subsequent dry deposition estimation (NADP, 2011a, b, c, d, e). Mercury monitoring networks and/or monitoring sites also exist in many other parts of the world (Sakata and Asakura, 2008; Sprovieri et al., 2010).

Dry deposition of $\mathrm{Hg}$ has been estimated using surrogatesurface measurements (Lyman et al., 2007; Marsik et al., 2007; Huang et al., 2012), micrometeorological measurements (Lindberg et al., 1998; Skov et al., 2006; Cobbett and Van Heyst, 2007), litterfall and throughfall measurements (Demers et al., 2007; Graydon et al., 2008; Risch et al., 2012a), and the inferential method (Xu et al., 1999; Miller et al., 2005; Lyman et al., 2007; Marsik et al., 2007; Bash et al., 2010; Engle et al., 2010). Due to the constant cycling of $\mathrm{Hg}$ between different atmosphere-surface media (Schroeder et al., 1989; Bash et al., 2007; Gustin et al., 2008), as well as technological limitations (Gustin and Jaffe, 2010; Lyman et al., 2010a, b), direct measurements of dry deposition are difficult and subject to larger errors (Zhang et al., 2009; Huang et al., 2012). Our incomplete understanding of other physical and chemical processes involving $\mathrm{Hg}$ also affect our ability to quantify $\mathrm{Hg}$ dry deposition (Lin et al., 2006, 2007; Gbor et al; 2007; Bullock et al., 2008; Pongprueksa et al., 2008; Zhang et al., 2012a). It is believed that the uncertainties in dry deposition estimates are larger than those in wet deposition estimates (Lindberg et al., 2007).

Mercury wet deposition collected from MDN were discussed in many earlier studies (Vanarsdale et al., 2005; Prestbo and Gay, 2009; Risch et al., 2012b). This is not the case for measurement-based dry deposition estimates; particularly at regional scales, measurements are very limited (Miller et al., 2005; Engle et al., 2010). With the availability of speciated $\mathrm{Hg}$ concentrations data from AMNet, i.e., gaseous elemental Hg (GEM), gaseous oxidized Hg (GOM) and particulate-bound $\mathrm{Hg}$ (PBM), it is now practical to provide more accurate estimations of $\mathrm{Hg}$ dry deposition for multiple locations. Furthermore, speciated $\mathrm{Hg}$ concentrations for dry deposition estimation is critical given the substantial differences in dry deposition velocities and ambient concentrations among the different $\mathrm{Hg}$ species (Keeler and Dvonch, 2005; Zhang et al., 2009; Engle et al., 2010; Amos et al., 2012).

The purpose of this study is to provide more accurate model estimates of speciated and total $\mathrm{Hg}$ dry deposition for multiple locations across eastern and central North America. Dry deposition estimates for the years 2008 and 2009 at 19 monitoring locations were generated using AMNet concentrations. The estimated dry deposition was assessed using limited surrogate-surface dry deposition measurements (Castro et al., 2012; Huang et al., 2012) and substantial annual litterfall $\mathrm{Hg}$ measurements collected at multiple locations (Risch et al., 2012a). Total dry deposition and contribu- tions from each individual $\mathrm{Hg}$ species are discussed in detail. Sources of $\mathrm{Hg}$ in litterfall and the relative importance of dry and wet deposition are also briefly discussed. The results are expected to provide useful information for the atmospheric $\mathrm{Hg}$ community as well as to ecological research.

\section{Methodology}

\subsection{Site information}

Nineteen sites located in central and eastern USA and Canada are included in this study (Table 1, Fig. 1). Note that Rochester (NY43) and Rochester_B (NY95) were collocated but operated by two different research groups. All sites except ELA belong to AMNet. Population density, land use category (LUC), etc. are shown in Table S1 (Supporting Information, "SI"), leading to site categorization. Ten sites are identified as rural sites and the remainder are urban/suburban sites. $\mathrm{Hg}$ point source emissions within a $100 \mathrm{~km}$ circle of each site are also shown in Fig. 1. It should be noted that point sources surrounding rural sites can be larger than those surrounding urban and suburban sites (e.g., Athens Super Site (OH02) and Piney Reservoir (MD08) versus nearby urban/suburban sites).

\subsection{Air concentration measurements}

Speciated Hg concentrations for the years 2008/2009 were used for this study. Available measurements are listed in Table 1. All data were collected using the Tekran Speciation systems (Models 1130, 1135, and 2537; Tekran Inc., Toronto, Canada; Landis et al., 2002). The detection limits were $1.0 \mathrm{pg} \mathrm{m}^{-3}$ for GOM and PBM and $0.01 \mathrm{ng} \mathrm{m}^{-3}$ for GEM (Baker and Bash, 2012). Specific site conditions, operations, data quality control, and data presentation can be found from individual studies, e.g., see Huang et al. (2010) for Rochester (NY95), Cheng et al. (2012) for ELA, and Mao and Talbot (2011) for Thompson Farm (NH06). A short description of data collection and analysis procedures can also be found in Zhang et al. (2012a).

All sites except ELA have been quality assured by AMNet. The AMNet quality assurance program uses field operator procedures and software review of data to produce the final reported data. Hourly and two-hourly observations, with intervening hours of instrument analysis, are coded by the software as either valid or invalid observations and then the data has a final review by the network site liaison and the site operator. Only valid data is released for distribution and website download.

For field operations, initial data review is conducted by trained, onsite operators following standard operating procedures (SOP) for harmonized operation of all of the instruments. The SOPs include documentation and reporting of instrument maintenance and status on a weekly, monthly, quarterly, and yearly basis. Additional procedures are in place to 


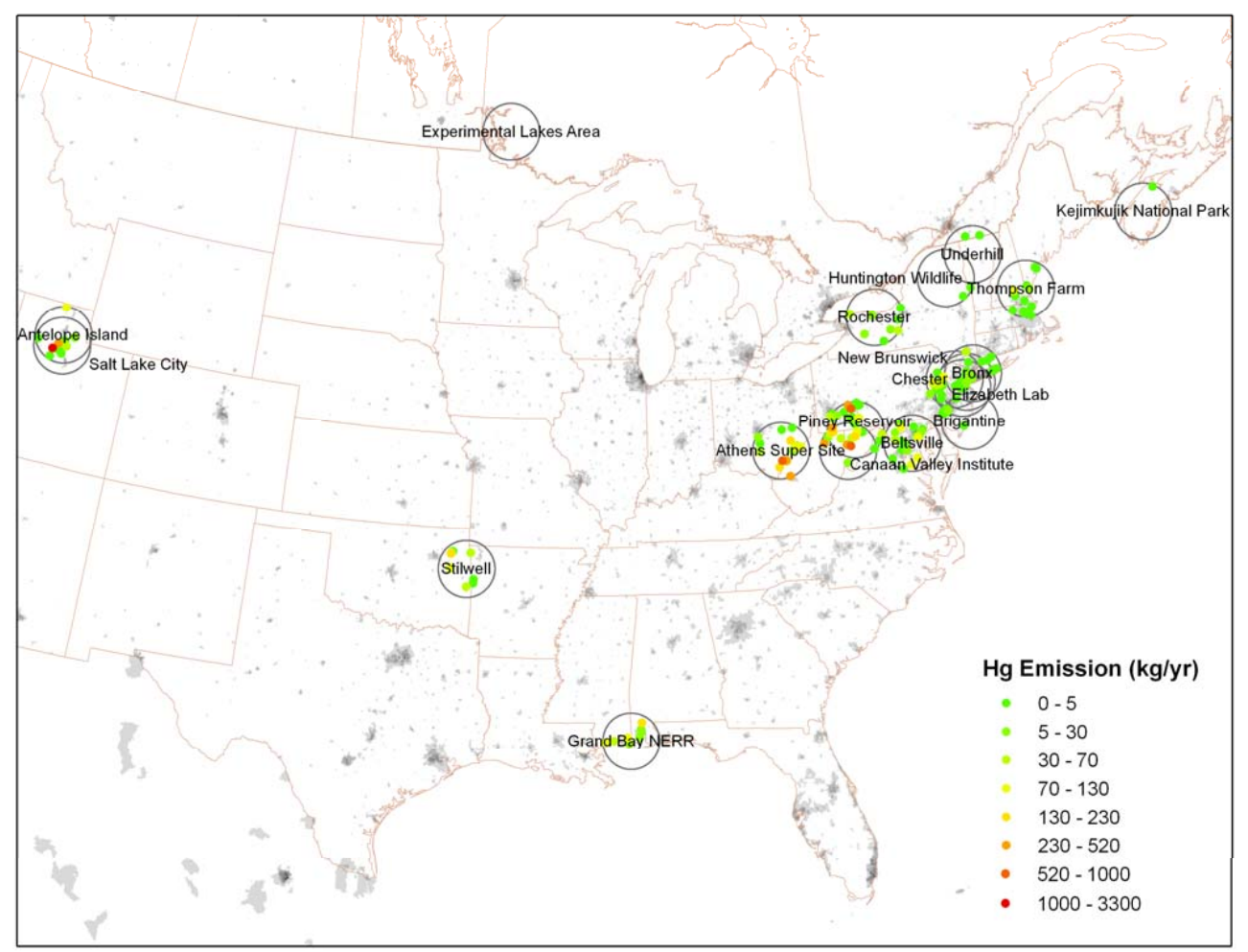

Fig. 1. Locations of the AMNet sites where $\mathrm{Hg}$ dry deposition were estimated. Also shown are $\mathrm{Hg}$ point source emissions with a $100 \mathrm{~km}$ circle of each site.

detect instrument problems using warning and action limits. An experienced site liaison is available for site consultation. Field operators regularly submit monthly site visit reports of instrument operation conditions, maintenance procedures completed, and problems noted. These records are incorporated into the data record for final valid/invalid observations (see NADP, 2011a, b, c, and d for specific steps).

Raw instrument data files are submitted regularly to the network for processing and quality assurance review. Hourly and two-hourly averages are determined from the raw observations using algorithms, with blank correction. The data is then subjected to an automated electronic quality assurance review procedure published in the Data Management Standard Operating Procedure document (NADP, 2011e). Examples of automated data flagging, covering a multitude of performance checks, include baseline stability, calibration response, contamination, sample volume, and variability between dual sample cartridges, to name a few.

\subsection{Dry deposition estimation}

The inferential method, i.e., an atmospheric species' dry deposition flux $(F)$ estimated as a product of its air concentration $(C)$ and its dry deposition velocity $\left(V_{\mathrm{d}}\right)$, was employed in this study to estimate $F$ for the three fractions of $\mathrm{Hg}$ (GEM, GOM, and PBM). Fluxes for each fraction were calculated at the same time resolution as their concentrations. Consid- ering that upward fluxes of GEM from re-emission of predeposited $\mathrm{Hg}$ and from natural emissions are frequently observed, net GEM dry deposition was used in the present study for constructing the dry deposition budget. Net GEM dry deposition was estimated as the difference between the calculated $F$ and modeled total re-emission plus natural emission from the Global/Regional Atmospheric Heavy Metals Model (GRAHM) (Dastoor and Larocque, 2004; Dastoor et al., 2008), as discussed in Zhang et al. (2012a).

$V_{\mathrm{d}}$ for GEM and GOM were calculated using the big-leaf dry deposition model described in Zhang et al. (2003):

$V_{\mathrm{d}}=\frac{1}{R_{\mathrm{a}}+R_{\mathrm{b}}+R_{\mathrm{c}}}$

where individual resistance terms include $R_{\mathrm{a}}$ as aerodynamic, $R_{\mathrm{b}}$ as quasi-laminar, and $R_{\mathrm{c}}$ as canopy resistance, respectively. $R_{\mathrm{c}}$ is parameterized as:

$\frac{1}{R_{\mathrm{c}}}=\frac{1-W_{\mathrm{st}}}{R_{\mathrm{st}}+R_{\mathrm{m}}}+\frac{1}{R_{\mathrm{ns}}}$

where $W_{\mathrm{st}}$ is the fraction of stomatal blocking under wet conditions, $R_{\mathrm{st}}$ is the stomatal resistance, calculated using a sunlit/shade stomatal resistance sub-model, $R_{\mathrm{m}}$ is the mesophyll resistance and is chosen as $500 \mathrm{~s} \mathrm{~m}^{-1}$ for GEM and 0 for GOM, and $R_{\mathrm{ns}}$ is the non-stomatal resistance which is a function of in-canopy, soil, and cuticle resistances. Cuticle 
Table 1. List of AMNet site information.

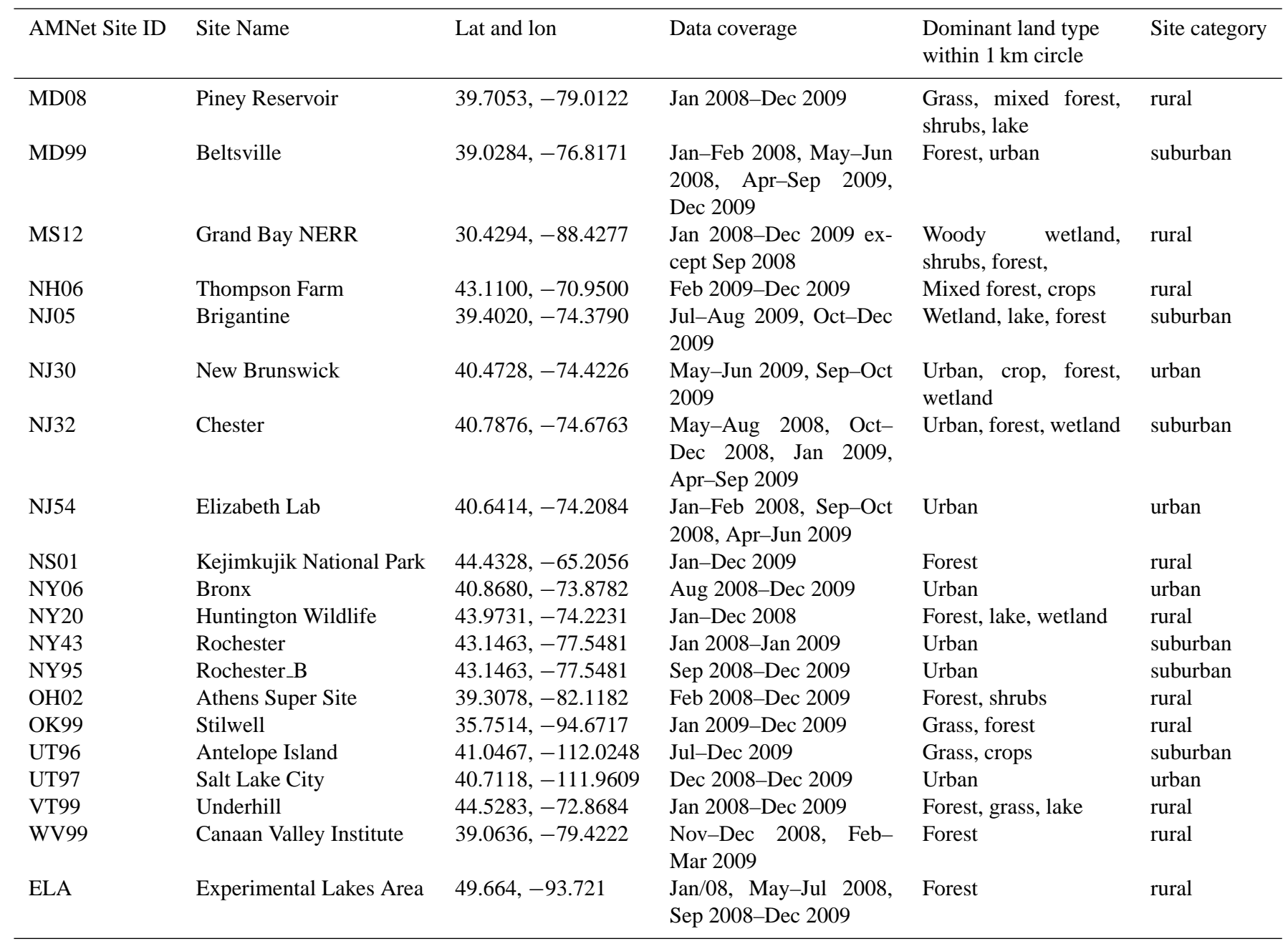

and soil resistances for GEM and GOM were scaled to those of $\mathrm{SO}_{2}$ and $\mathrm{O}_{3}$ using the following equation with two scaling parameters chosen as $\alpha=0$ and $\beta=0.1$ for GEM and $\alpha=10$ and $\beta=10$ for GOM:

$$
\frac{1}{R_{x}(i)}=\frac{\alpha(i)}{R_{x}\left(\mathrm{SO}_{2}\right)}+\frac{\beta(i)}{R_{x}\left(\mathrm{O}_{3}\right)}
$$

Note that the values of $R_{\mathrm{m}}, \alpha$, and $\beta$ chosen for GOM and GEM are empirical numbers that can be theoretically supported by the species' solubility and reactivity, an approach used in previous dry deposition parameterizations for commonly-studied gaseous species in air quality models (Wesely, 1989; Zhang et al., 2002). More importantly, these values give the right range of $V_{\mathrm{d}}$ values when compared to a review of available measurements (Zhang et al., 2009). The $\beta$ value for GEM was originally assigned a value of 0.2 in Zhang et al. (2009). Sensitivity tests in GRAHM, based on the comparison between modeled and measured GEM concentrations, suggest that this value is probably too big (Zhang et al., 2012a). To avoid overestimating $V_{d}$ for GEM, a value of 0.1 is used for $\beta$ in the present study. Parameters for GOM are the same as those for $\mathrm{HNO}_{3}$, a common approach used in previous studies (Bullock et al., 2002; Miller et al., 2005; Marsik et al., 2007).

$V_{\mathrm{d}}$ for PBM was calculated using the size-segregated particle dry deposition model described in Zhang et al. (2001):

$V_{\mathrm{d}}=V_{\mathrm{g}}+\frac{1}{R_{\mathrm{a}}+R_{\mathrm{S}}}$

where $V_{\mathrm{g}}$ is the gravitational settling velocity, and $R_{\mathrm{S}}$ is the surface resistance parameterized as a function of collection efficiencies from Brownian diffusion, impaction, and interception mechanisms. A log-normal size distribution for PBM was assumed and $V_{\mathrm{d}}$ for each size bin was calculated and then aggregated into the bulk $V_{\mathrm{d}}$ based on the mass size distribution. A geometric mass mean diameter of $0.38 \mu \mathrm{m}$ and a geometric standard deviation of 2.2 were used for the lognormal size distribution. This assumption is thought to be reasonable for inland sites where PBM is mainly associated with fine particles; however, $V_{\mathrm{d}}$ for coastal sites might be 
underestimated where PBM are frequently associated with coarse particles.

The original model of Zhang et al. (2001) used 15 LUCs, but here we used 26 LUCs (Table S1), following Zhang et al. (2003). Input parameters in Zhang et al. (2001) were given for each LUC and for five seasonal categories. This approach was discarded here; instead, the same approach developed in Zhang et al. (2003) was used. That is, for any input parameter $(X)$ changing with season, a maximum value $\left(X_{\max }\right)$ and a minimum value $\left(X_{\min }\right)$ were provided and were then interpolated to any day of the year based on the annual variation of the leaf area index (LAI):

$X(t)=X(\min )+\frac{\mathrm{LAI}(t)-\mathrm{LAI}(\min )}{\mathrm{LAI}(\max )-\mathrm{LAI}(\min )}[X(\max )-X(\min )]$

where $t$ represents any day of the year, and $\mathrm{LAI}(\mathrm{min})$ and $\mathrm{LAI}(\max )$ represent minimum and maximum LAI values, respectively, during the year. Input parameters for the particle dry deposition model that need interpolation include a parameter for the characteristic radius of collectors, a parameter for calculating the collection efficiency by Brownian diffusion, and a parameter for calculating the collection efficiency by impaction (Zhang et al., 2001). Roughness for each LUC for the particle dry deposition model is the same as for the gaseous dry deposition model, as described in Zhang et al. (2003).

The meteorological data used for driving the dry deposition models were from the archived data produced by the Global Environmental Multiscale model, which is the Canadian weather forecast model, an approach described in Brook et al. (1999). Meteorological variables representing the same time period as the $\mathrm{Hg}$ air concentration measurements for the surface and the first model-layer, typically at $40-50 \mathrm{~m}$ in height, are available hourly at a horizontal grid resolution of $15 \mathrm{~km}$ by $15 \mathrm{~km}$. Data for model grids containing the measurement sites were extracted from the archived data to calculate hourly $V_{\mathrm{d}}$. Area-weighted land types within a $1 \mathrm{~km}$ radius of each site were used to calculate $V_{\mathrm{d}}$ (see Table 1 and Table S1).

\subsection{Litterfall and wet deposition measurements}

To assess the reasonableness of these dry deposition estimates, and explore the sources of $\mathrm{Hg}$ in litterfall, estimated speciated and total $\mathrm{Hg}$ dry deposition were compared with collected litterfall $\mathrm{Hg}$. The total net $\mathrm{Hg}$ dry deposition to a forest is the sum of the $\mathrm{Hg}$ in the litterfall, the $\mathrm{Hg}$ captured by the canopy and then emitted back to the atmosphere, the $\mathrm{Hg}$ washed off the canopy by precipitation (throughfall), and the $\mathrm{Hg}$ deposited directly to the underlying soils. Thus, litterfall deposition may be treated as the low-end estimation of the total $\mathrm{Hg}$ dry deposition to a forest, if $\mathrm{Hg}$ emission from the underlying soil is limited. On the other hand, if soil $\mathrm{Hg}$ emissions are high and the ambient $\mathrm{Hg}$ concentrations above the forest are low, the litterfall $\mathrm{Hg}$ might be higher than the dry deposition above the canopy due to the interception of emitted $\mathrm{Hg}$ by the forest leaves. Based on the above arguments, it is reasonable to assume that total dry deposition and litterfall deposition should be similar on regional scales, although the differences can be very large at individual sites. Thus, we compared the estimated dry deposition with measured litterfall deposition on a regional-scale and at six collocated sites (see below for details). A better comparison would be to compare the estimated dry deposition with the litterfall plus throughfall deposition, as was also done for ELA in this study.

Three-year average $\mathrm{Hg}$ litterfall measurements during 2007-2009 at 23 selected MDN sites, as described in detail by Risch et al. (2012a), were used for this study. The site information for the litterfall measurements is listed in Table S2. Litterfall measurements were also made at the ELA site (Graydon et al., 2008). Note that many AMNet sites are not collocated with MDN sites and thus are not at the same sites where the litterfall data were collected. Only six sites have both dry deposition estimation and litterfall measurements (Table 2).

Wet deposition collected by MDN during the years 20072009 were also used for the purpose of quantifying the relative importance of dry and wet deposition. A wet deposition map was created using the three-year average wet deposition of non-urban MDN monitoring sites. For this data, non-urban sites were defined as less than 400 people per square kilometer $\left(\mathrm{km}^{2}\right)$ within a $15 \mathrm{~km}$ radius of the site. The interpolated annual sums of $\mathrm{Hg}$ wet deposition were computed for an array of regularly spaced grid values using the sites that were within $300 \mathrm{~km}$ of each grid point. The boundary of the interpolated area was trimmed at the coast line and smoothed for values up to $300 \mathrm{~km}$ from the outermost data points over land.

\section{Results and discussion}

\subsection{Air concentrations}

Annual average concentrations among the sites during 20082009 ranged from 1.1 to $22.6 \mathrm{pg} \mathrm{m}^{-3}$ for GOM, 2.9 to $17.1 \mathrm{pg} \mathrm{m}^{-3}$ for PBM, and 1.2 to $2.1 \mathrm{ng} \mathrm{m}^{-3}$ for GEM (Fig. 2a, b). As expected, the species having the shortest lifetimes had the largest geographical variations. GOM only contributed $0.1-1.5 \%$ to the total gaseous $\mathrm{Hg}(\mathrm{GOM}+\mathrm{GEM})$ at these locations.

The highest annual concentrations for GEM were detected at several urban and suburban sites (e.g., 1.79 to $2.13 \mathrm{ng} \mathrm{m}^{-3}$ for NJ32, NJ54, NJ30, and UT97), whereas the lowest annual concentrations were detected in more remote rural areas (e.g., 1.24 to $1.37 \mathrm{ng} \mathrm{m}^{-3}$ for ELA, NH06, OK99, and NS01). The annual GEM concentrations did not differ significantly between suburban and rural sites in the north-eastern 
Table 2. Estimated speciated and total dry deposition $\left(\mu \mathrm{g} \mathrm{m}^{-2} \mathrm{yr}^{-1}\right)$ and measured litterfall deposition $\left(\mu \mathrm{g} \mathrm{m}^{-2} \mathrm{yr}^{-1}\right)$ at six sites. The last column represents upper-end estimation of GOM+PBM dry deposition by incorporating the potential uncertainties.

\begin{tabular}{lccccccc}
\hline Site ID & GOM & PBM & GOM+PBM & Net GEM & Total dry deposition & Litterfall & Increased GOM+PBM \\
\hline MD08 & 7.8 & 0.30 & 8.1 & 6.8 & 14.9 & 15.3 & 16.8 \\
MD99 & 1.3 & 0.32 & 1.6 & 9.0 & 10.6 & 15.5 & 3.9 \\
OH02 & 3.0 & 0.38 & 3.4 & 9.9 & 13.3 & 18.8 & 7.5 \\
VT99 & 0.72 & 0.41 & 1.1 & 11.7 & 12.8 & 11.3 & 3.1 \\
WV99 & 3.6 & 0.44 & 4.0 & 8.2 & 12.2 & 9.9 & 9.0 \\
ELA & 0.49 & 0.25 & 0.74 & 15.6 & 16.3 & 8.6 & 2.0 \\
\hline
\end{tabular}

USA due to the many point and area sources in this region (Fig. 1) and the long atmospheric lifetime of GEM. The geographical variations in the annual GEM were within a factor of 1.8 among all of the sites discussed here. As with GEM, the lowest annual concentrations of GOM and PBM were also detected at the same remote rural sites (ELA, NH06, OK99, and NS01); however, this was not the case for the highest concentrations of GOM and PBM. For example, UT97, MD08, WV99, and OH02 had the highest GOM concentrations and UT96, UT97, and NJ54 had the highest PBM concentrations. Similar to GEM, quite a few rural sites (e.g., WV99, OH02, and MD08) had GOM and PBM concentrations that were comparable to the concentrations at the urban and suburban sites. Among all of the sites, the geographical variations in the annual GOM were within a factor of 20 , while the annual PBM were within a factor of 6 .

With the exception of a few urban sites (NJ05, NJ30, NJ32, and UT97), GEM had higher concentrations in the cold seasons (spring and winter) than in the hot seasons (summer and fall) (Fig. S1 and Table S3). The seasonal variations in GEM (the ratio between the highest and the lowest seasonal concentrations) were in the range of a factor of 1.08 to 1.62 , depending on the location. Seasonal variations of GOM and PBM were highly variable and were also much larger than those of GEM. At many sites, GOM concentrations in the spring were much higher than during any other season. At an urban site (UT97), GOM had slightly higher concentrations in the summer and fall compared to those in the winter and spring. At two other urban/suburban sites (NJ05 and UT96), GOM had much higher concentrations in the summer compared to the fall and winter, but the spring data at these two sites were not available. The seasonal variations in GOM were in the range of a factor of 1.4 to 11.2 at all of the locations expect at NJ05, where it was a factor of 22. For PBM, the highest seasonal concentrations were observed in the winter and the lowest were in the fall at the majority of the 19 sites. This phenomenon was also observed by Amos et al. (2012) and an empirical PBM-GOM partitioning model was generated to describe this variability in their study. The seasonal variations in PBM were in the range of a factor of 2.2 to 11.6 , depending on the location. The differences and similarities among the three $\mathrm{Hg}$ species in their geographical
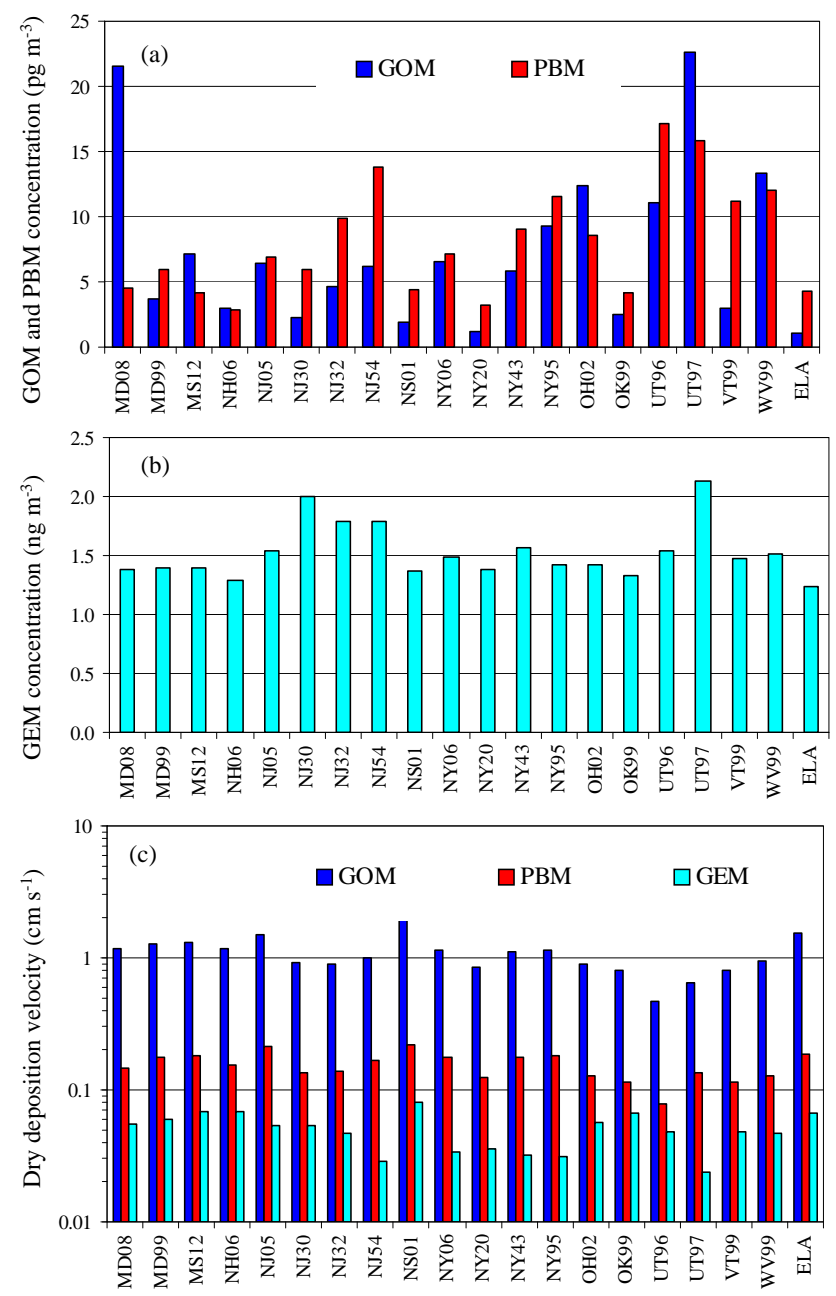

Fig. 2. Annual average concentrations for GOM, PBM $\left(\mathrm{pg} \mathrm{m}^{-3}\right)$ and GEM $\left(\mathrm{ng} \mathrm{m}^{-3}\right)$ and annual dry deposition velocity $\left(V_{\mathrm{d}}\right.$ in $\mathrm{cm} \mathrm{s}^{-1}$ ).

and seasonal patterns were caused by many factors including sources, transportation, chemical transformation, and removal processes (Huang et al., 2010; Mao and Talbot et al., 2011; Amos et al., 2012; Cheng et al., 2012). 

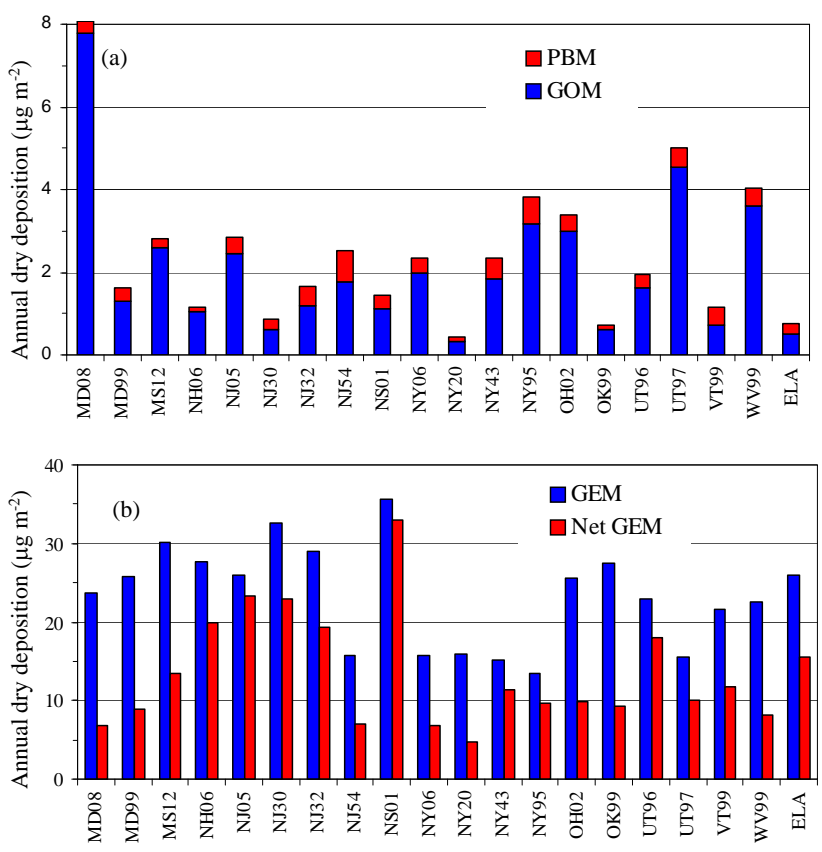

Fig. 3. Annual average speciated dry deposition fluxes $\left(\mu \mathrm{g} \mathrm{m}^{-2}\right)$. Net GEM flux is the GEM dry flux minus GRAHM modeled annual GEM re-emission and natural emission fluxes.

\section{2 deposition velocities}

Based on existing models/parameterizations constructed for the calculation of $\mathrm{Hg} V_{\mathrm{d}}$ (e.g., Zhang et al., 2009 and references therein), if meteorological conditions are similar, GOM and PBM should have larger $V_{\mathrm{d}}$ values over surfaces with larger roughness lengths (and thus higher friction velocities) than over smoother surfaces; and GEM should have larger $V_{\mathrm{d}}$ values over canopies with larger LAI than over any other surface. For example, the estimated annual $V_{\mathrm{d}}$ of GOM over forest-dominated sites was in the range of 1.4$2.0 \mathrm{~cm} \mathrm{~s}^{-1}$, and was close to $1.0 \mathrm{~cm} \mathrm{~s}^{-1}$ over urban areas (Fig. 2c). Values lower than $0.8 \mathrm{~cm} \mathrm{~s}^{-1}$ were also calculated for a few sites with small roughness lengths and/or weak wind speeds. In general, estimated $V_{\mathrm{d}}$ of PBM was five to ten times smaller than $V_{\mathrm{d}}$ of GOM. Estimated annual $V_{\mathrm{d}}$ for GEM was mostly in the range of $0.05-0.08 \mathrm{~cm} \mathrm{~s}^{-1}$ over vegetated surfaces and below $0.05 \mathrm{~cm} \mathrm{~s}^{-1}$ over urban areas, and was generally 20-30 times smaller than those of GOM, and 2-6 times smaller than PBM. Calculated $V_{\mathrm{d}}$ values shown here are well within the range of published estimates (Zhang et al., 2009).

The estimated seasonal (or monthly) average $V_{\mathrm{d}}$ for GOM and PBM was higher during seasons with strong wind speeds. Note that $R_{\mathrm{a}}, R_{\mathrm{b}}, R_{\mathrm{ns}}$ and $R_{\mathrm{s}}$, defined in Sect. 2.4, are all smaller under stronger wind conditions. As for GEM, the $V_{\mathrm{d}}$ was higher over forests and during full growing seasons than over other surfaces or during other seasons due to the dominant effect of LAI on $V_{\mathrm{d}}$. As an example, average diurnal and monthly $V_{\mathrm{d}}$ at the Kejimkujik site (NS01; a remote coastal site with forest coverage) are shown in Fig. S2 in the Supplement. The wind was stronger in the winter than in the summer at this location and thus $V_{\mathrm{d}}$ values of GOM and PBM were higher in the winter. On the other hand, $V_{\mathrm{d}}$ of GEM was much higher in the spring and summer than in the winter due to the dominant effect of LAI. The relative changes (compared to their own annual average values) in the seasonal and diurnal $V_{\mathrm{d}}$ were also much larger for GEM (see normalized $V_{\mathrm{d}}$, Fig. S2 in the Supplement).

\subsection{Estimated dry deposition fluxes}

The estimated annual dry deposition of GOM+PBM ranged from 0.4 to $8.1 \mu \mathrm{g} \mathrm{m}^{-2} \mathrm{yr}^{-1}$ at the 19 sites. GOM contributed 0.3-7.8 $\mu \mathrm{g} \mathrm{m}^{-2} \mathrm{yr}^{-1}$ to these fluxes, whereas PBM contributed only $0.1-0.8 \mu \mathrm{g} \mathrm{m}^{-2} \mathrm{yr}^{-1}$ (Fig. 3a). The estimated annual GEM dry deposition was in the range of 13 to $35 \mu \mathrm{g} \mathrm{m}^{-2} \mathrm{yr}^{-1}$ (Fig. 3b), much higher than originally assumed in many previous studies. Earlier studies either simply excluded GEM in the dry deposition budget or used extremely small $V_{\mathrm{d}}$ values (Engle et al., 2010; Baker and Bash, 2012). Despite the high $V_{\mathrm{d}}$ values used for GEM in the present study, dry deposition estimates for GEM are still believed to be conservative estimates, as mentioned in Sect 2.3. The very high dry deposition fluxes of GEM are certainly due to the two to three orders of magnitude higher concentrations of GEM compared to those of GOM+PBM. As discussed in Zhang et al. (2012a), GEM re-emission was around half of the GEM dry deposition on regional scales in eastern North America, although the relative importance of re-emission/dry deposition varied significantly with locations. Using GRAHM modeled GEM re-emission and natural emission, net GEM dry deposition fluxes were estimated to be in the range of 4.8 to $23.3 \mu \mathrm{g} \mathrm{m}^{-2} \mathrm{yr}^{-1}$ for all of the sites except for NS01, at $33 \mu \mathrm{g} \mathrm{m}^{-2} \mathrm{yr}^{-1}$ (Fig. 3b). The estimated net GEM dry deposition was still much higher than the estimated GOM+PBM dry deposition at the majority of the monitoring sites. It is noted that at several sites (MD08, UT07, WV99), net GEM dry deposition and dry deposition of GOM+PBM were in a similar range of values (within a factor of 2).

Estimated dry deposition of GOM+PBM was mostly two to five times higher at sites near significant $\mathrm{Hg}$ emissions (e.g., point sources $>200 \mathrm{~kg} \mathrm{yr}^{-1}$ ) than at the remote sites, but this is not the case for the estimated net GEM dry deposition. This is due to the strong dependence of GEM $V_{\mathrm{d}}$ on land types, meteorological conditions, and the small geographical variations of the ambient GEM concentrations. For example, the dry deposition of GOM+PBM was among the lowest at several rural/remote sites (ELA, Kejimkujik, Underhill), while the net GEM dry deposition at these locations was among the highest. Thus, the total dry deposition does not necessarily correlate with proximity to emission sources due to the dominance of GEM dry deposition. 
These estimated annual GOM dry deposition amounts were in the same range as those in several previous studies based on measured ambient GOM concentrations. For example, Engle et al. (2010) and Lombard et al. (2011) obtained GOM dry depositions in the range of 0.5 to $5.3 \mu \mathrm{g} \mathrm{m}^{-2} \mathrm{yr}^{-1}$ at multiple locations in central and eastern USA; the only exception was for an urban site (Illinois) with estimated GOM deposition of $52 \mu \mathrm{g} \mathrm{m}^{-2} \mathrm{yr}^{-1}$, due to extremely high GOM concentrations. Here, estimated GOM dry deposition ranged from 0.3 to $4.5 \mu \mathrm{g} \mathrm{m}^{-2} \mathrm{yr}^{-1}$ for all of the sites except for MD08, which was $7.8 \mu \mathrm{g} \mathrm{m}^{-2} \mathrm{yr}^{-1}$.

The estimated GOM+PBM dry deposition in the present study seems to be supported by limited field measurements using surrogate surfaces at several sites (MD08, NY20, and NY95). For example, Castro et al. (2012) obtained an annual dry deposition of $3.2 \mu \mathrm{g} \mathrm{m}^{-2} \mathrm{yr}^{-1}$ for GOM at MD08. However, the average GOM concentration during their study period (September 2009 to October 2010) was $9.1 \mathrm{pg} \mathrm{m}^{-3}$. In comparison, the annual average GOM concentration from the present study was $21.5 \mathrm{pg} \mathrm{m}^{-3}$ and the estimated dry deposition was $7.8 \mu \mathrm{g} \mathrm{m}^{-2} \mathrm{yr}^{-1}$ (Figs. 2, 3). Model estimations agree reasonably well with surrogatesurface measurements at this site after concentration adjustments (e.g., $<10 \%$ difference). Measured GOM+PBM dry deposition at NY20 during April 2009 to January 2010 was $0.8 \mu \mathrm{g} \mathrm{m}^{-2} \mathrm{yr}^{-1}$ and at NY95 during January to November 2009 was $4.4 \mu \mathrm{g} \mathrm{m}^{-2} \mathrm{yr}^{-1}$ (Huang et al., 2012). In comparison, the estimated dry deposition was $0.4 \mu \mathrm{g} \mathrm{m}^{-2} \mathrm{yr}^{-1}$ at NY20 during 2008 and was $3.9 \mu \mathrm{g} \mathrm{m}^{-2} \mathrm{yr}^{-1}$ at NY95 for September 2008 to December 2009. At NY20, the average GOM concentration was $1.9 \mu \mathrm{g} \mathrm{m}^{-3}$ during their study period and was $1.2 \mu \mathrm{g} \mathrm{m}^{-3}$ during our study period. The differences in the dry deposition estimations between theirs and ours studies were smaller than $30 \%$ after concentration adjustments. The agreement was even better $(\sim 10 \%$ difference) at NY95. It is noticed that the GOM concentrations at NY20 were very low and thus both the concentration and dry deposition measurements were expected to have large errors (more discussion in Sect. 3.4). Surrogate-surface measurements conducted at other locations in the USA have also suggested a similar range of GOM dry deposition (e.g., Lyman et al., 2007; Marsik et al., 2007).

The estimated dry deposition of GOM+PBM discussed above is substantially smaller than those simulated by $\mathrm{Hg}$ transport models (Zhang et al., 2012a). The surface-layer GOM and PBM concentrations simulated by the majority of the $\mathrm{Hg}$ transport models were higher by a factor of 2 to 10 compared to the recently-available AMNet-measured speciated concentrations in the Great Lakes region (Baker and Bash, 2012; Zhang et al., 2012a) and this had a big impact on the modeled dry deposition. Zhang et al. (2012a) suggested that the emission inventory and the partitioning between GOM and PBM were the major reasons causing the large over-prediction of GOM and PBM concentrations. More recently, Kos et al. (2011) modified the GRAHM model after extensive sensitivity tests to improve the predicted surfacelayer GOM and PBM concentrations. As a result, wet deposition prediction was also improved when compared to the MDN measurements. This further suggests that previously modeled $\mathrm{Hg}$ dry deposition of GOM+PBM were overestimated and were not as realistic as the values estimated using AMNet monitored speciated concentration data. It is thus believed that the dry deposition estimated using AMNet data is more realistic than those estimated from $\mathrm{Hg}$ transport models

\subsection{Potential uncertainties in the estimated dry deposition}

Uncertainties in the estimated dry deposition can come from uncertainties in both the measured concentrations and the modeled $V_{\mathrm{d}}$ values. The instruments collecting speciated $\mathrm{Hg}$ concentrations are subject to analytical artifacts which may cause measurement errors on the order of $10-40 \%$ for all of the $\mathrm{Hg}$ species (e.g., Gustin and Jaffe, 2010; Lyman et al., 2010a, b; Huang et al., 2012). For example, a lower efficiency for capturing GOM was recently found by using $\mathrm{KCl}$-coated quartz denuders, a standard method in Tekran speciation systems for GOM measurements. The GOM concentration was likely biased low, e.g., up to $55 \%$ under high ozone concentration conditions (Lyman et al., 2010b). At the ELA site, automated and manual calibrations agreed within, on average, $4.9 \%$ for GEM concentrations (Cheng et al., 2012). At an urban site in Cleveland, Ohio, a recent study comparing the Tekran system and passive air samples found the relative percentage difference to be in the range of 4.0 to $44 \%$ for GEM and 1.5 to $41 \%$ for GOM during a 20-day experimental period (Huang et al., 2012). Apparently, large percentage errors were associated with low concentration cases. Different air sampler designs can increase these differences (Lyman et al., 2010a). Considering that cases with the highest concentrations dominate the annual dry deposition, the uncertainties in the annual dry deposition estimation caused by the uncertainties in the measured concentrations should be lower than $40 \%$.

Uncertainties in the calculated $V_{\mathrm{d}}$ are expected to be larger than in the measured concentrations. These uncertainties came from variations in the model theory, errors in the meteorological data used to drive the model, and the inaccurate representation of the surface characteristics. For example, many of the AMNet sites are located in areas of complex topography; the $15 \mathrm{~km}$ by $15 \mathrm{~km}$ average meteorological data may depart considerably from the specific meteorological conditions at an observation site.

If the dry deposition of GOM does behave like $\mathrm{HNO}_{3}$, as frequently assumed in previous studies (Bullock et al., 2002; Miller et al., 2005; Marsik et al., 2007), then the uncertainties in the GOM $V_{\mathrm{d}}$ should be generally within a factor of 2 , as shown by a recent model intercomparison study (Flechard et al., 2011). No systematic error is identified in the estimated GOM dry deposition across all of the sites. The relatively 
good agreement (e.g., within $30 \%$ difference) between the model estimates and the surrogate-surface measurements at several sites discussed in Sect. 3.3 support this. However, an earlier study by Lyman et al. (2007), using a modified version of the present model, found the model underestimated GOM dry deposition by a factor of 2 or more compared with their surrogate-surface measurements. They also stated that the model results were sensitive to environmental and meteorological conditions, and application of the model to other land use categories or climatological conditions would likely yield different results. Huang et al. (2012), on the other hand, found much closer agreements between the model estimates and the surrogate-surface measurements, with the model estimates lower by $10 \%$ to $50 \%$ (or a factor of 2), depending on the location and the sampling method, rather than on the measurements. The same study also found the dry deposition measured using different surrogate surfaces differed by nearly a factor of 1.8. Thus, it is believed that uncertainties in modeled and measured dry deposition are on a similar order of magnitude and are mostly within a factor of 2 . It is worth pointing out that on-site meteorology was used in Huang et al. (2012) while forecasted meteorology was used in the present study in the calculation of $V_{\mathrm{d}}$. Average $V_{\mathrm{d}}$ for the three sites studied in Huang et al. (2012) were 0.02$0.06 \mathrm{~cm} \mathrm{~s}^{-1}$ for GEM, $0.53-1.63 \mathrm{~cm} \mathrm{~s}^{-1}$ for GOM, and $0.03-$ $0.1 \mathrm{~cm} \mathrm{~s}^{-1}$ for PBM. These values were comparable with the values obtained in the present study (Fig. 2).

The PBM dry deposition fluxes presented in this study are likely conservative estimates since the ambient data collected by a Tekran instrument excluded coarse particle $\mathrm{Hg}$. As shown in a recent study on trace metal dry deposition, coarse particles play an important and sometimes dominate role in the dry deposition budget (Zhang et al., 2012b). Assuming $30 \%$ of the total PBM is in coarse particles (Landis and Keeler, 2002), PBM dry deposition needs to be adjusted by a factor of 2 or more depending on the actual particle size distribution, considering that coarse particle $V_{\mathrm{d}}$ might be substantially higher than fine particle $V_{\mathrm{d}}$. At coastal locations where coarse PBM can be as high as $50 \%$ (Feddersen et al., presented in the 2010 AGU fall meeting, San Francisco), the estimated dry deposition needs to be adjusted by a factor of 3 to 5 . However, the uncertainties in the sum of GOM+PBM dry deposition are likely to be within a factor of 2 considering PBM only contributes a small fraction to the dry deposition of GOM+PBM (more discussion in Sect. 3.5).

Due to the limited knowledge of GEM dry deposition and its bi-directional exchange features, uncertainties in the estimated GEM dry deposition are difficult to quantify and can be very large under certain circumstances. Further assessments using litterfall measurements are presented in Sect. 3.5. The dry deposition estimates presented in this study are believed to be conservative estimates for all of the three forms of $\mathrm{Hg}$ at the majority of the locations based on the parameters given for the $V_{\mathrm{d}}$ calculations. However, it is possible that the net GEM dry deposition at a few of the sites might be overestimated if the GEM emission is underestimated. Several mercury transport models in North America have all used the same scheme of Shetty et al. (2008) to describe GEM emissions from natural surfaces (e.g., Dastoor and Larocque, 2004; Lin et al., 2006). The uncertainties in GEM remission cannot be quantified in the present study, and should be done by the mercury modeling community in the future.

Despite the uncertainties in the estimated dry deposition of all of the species, the major conclusions presented above remain effective. For example, even doubling the estimated GOM+PBM deposition would not change the relative importance of GOM+PBM and net GEM dry deposition.

\subsection{Comparison with litterfall measurements}

Dry deposition of GOM+PBM, net dry deposition of GEM, and litterfall measurements were marked on a wet deposition map for easy comparison (Fig. 4). Direct dry deposition measurements for GEM are limited and there are no data available at multiple locations or at regional scales to evaluate the estimated net GEM dry deposition. However, litterfall measurements can be used to qualitatively (and to some extent, quantitatively) assess and constrain the estimated GEM and total dry deposition. A few factors need to be considered. The estimated dry deposition considered all of the land types surrounding the sites, included deposition to all media (leaves, tree branches, soils), and covered the whole year period; in contrast, the litterfall deposition was only for forests, only considered deposition to leaves, and only covered seasons with leaves for deciduous forests (for the coniferous forest at the ELA site, year-round litterfall and throughfall measurements were made). Additionally, the modeled dry deposition represented net dry deposition above the canopy; in contrast, litterfall deposition included $\mathrm{Hg}$ deposition from above the canopy as well as the interception of soil-emitted $\mathrm{Hg}$.

At all of the AMNet sites and the ELA site, the estimated total dry deposition (GOM+PBM+net GEM) was in the range of 5.2 to $26 \mu \mathrm{g} \mathrm{m}^{-2} \mathrm{yr}^{-1}$ (except for NS01, $34.4 \mu \mathrm{g} \mathrm{m}^{-2} \mathrm{yr}^{-1}$ ), with GOM+PBM contributing only 0.4 to $8.1 \mu \mathrm{g} \mathrm{m}^{-2} \mathrm{yr}^{-1}$ to this total (Fig. 4). Litterfall deposition was in the range of 4 to $19 \mu \mathrm{g} \mathrm{m}^{-2} \mathrm{yr}^{-1}$ from all of the sites (Risch et al., 2012a). In general, the model-estimated dry deposition was in the same range as the $\mathrm{Hg}$ measured in annual litterfall in eastern and central USA.

For the six sites (MD08, MD99, OH02, VT99, WV99, ELA) with both litterfall measurements and dry deposition estimates (Table 2), the estimated total dry deposition was in the range of 11 to $16 \mu \mathrm{g} \mathrm{m}^{-2} \mathrm{yr}^{-1}$ and the measured litterfall $\mathrm{Hg}$ was in the range of 9 to $19 \mu \mathrm{g} \mathrm{m}^{-2} \mathrm{yr}^{-1}$. At the two forest-dominated sites (VT99 and WV99), the estimated total dry deposition was not significantly different (e.g., 10-20\% difference) from the measured litterfall $\mathrm{Hg}$ and the estimated net GEM dry deposition explains $>80 \%$ of the litterfall $\mathrm{Hg}$. At another three sites (MD08, MD99 and OH02), the net 


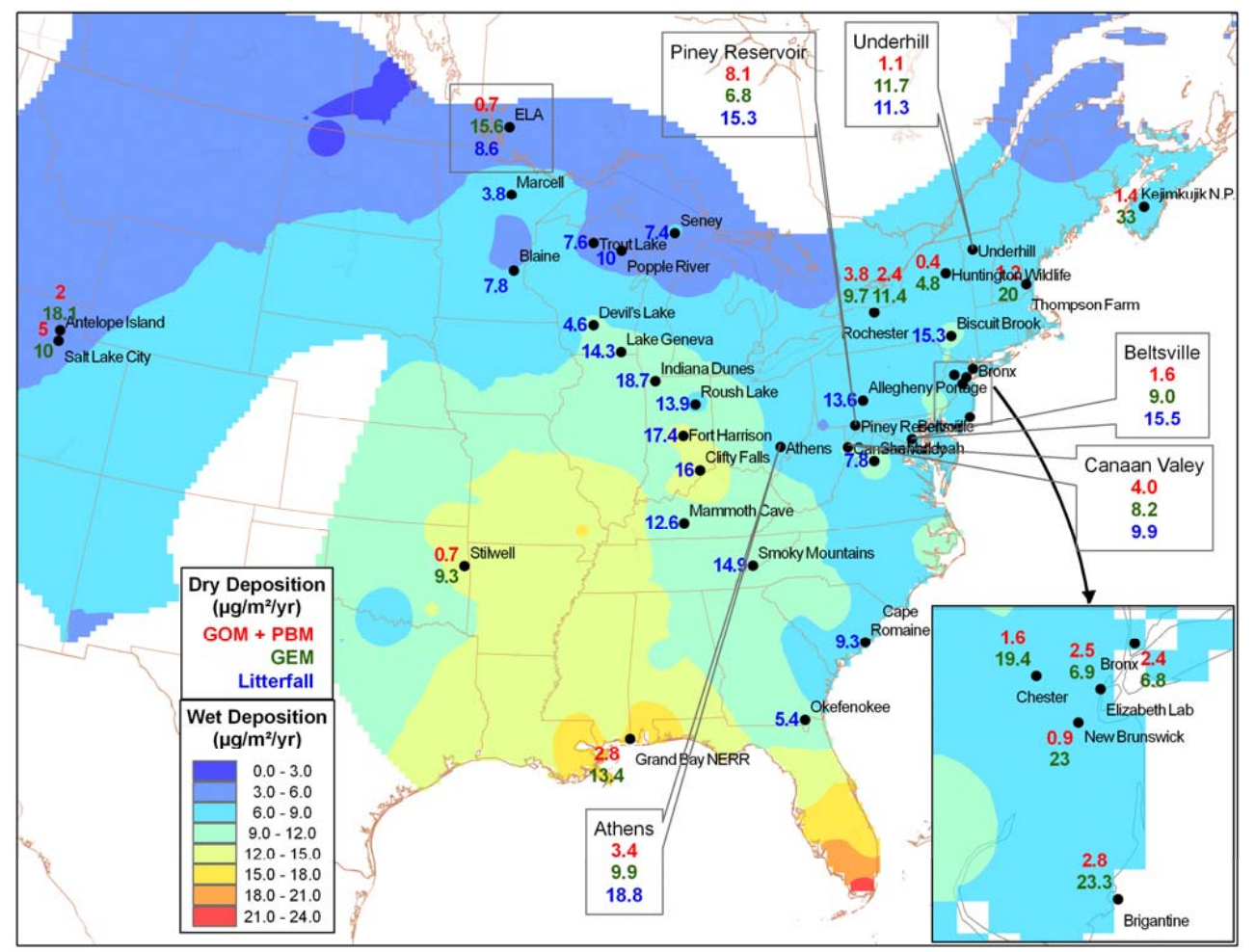

Fig. 4. Comparisons of estimated dry deposition of GOM+PBM and GEM from 2008 and 2009 speciated concentrations with litterfall deposition collected during 2007-2009 and with wet deposition monitored during 2007-2009.

GEM dry deposition explains $45-60 \%$ of the litterfall deposition while the total dry deposition explains $\sim 70-100 \%$ of the litterfall deposition. There are several possibilities causing these discrepancies: (1) dry deposition of GOM+PBM and the net GEM were underestimated due to various reasons, including the overestimation of GEM re-emission; (2) if only using forest canopies for estimating dry deposition at these three sites (nearly $50 \%$ of the areas were not forests at these three sites as shown in Table S1), the net GEM dry deposition would be higher and closer to the litterfall deposition ( $V_{\mathrm{d}}$ is higher over forests than over any other surfaces); (3) it is also noted that the modeled re-emissions of GEM at these three sites were among the highest (MD08, OH02, MD99 in Fig. 2b); thus, part of the litterfall deposition might be from the interception of re-emitted GEM from the soil, but may not be reflected in the modeled net GEM dry deposition.

Among the six collocated sites, ELA is the only site having net GEM dry deposition higher (by a factor of 1.8) than the litterfall deposition, which should be the case for all of the locations with low soil $\mathrm{Hg}$ emissions. Note that ELA is a remote site with few Hg point sources (Fig. 1). Besides, the modeled GEM emission from the natural surfaces at this site was also very low (see Fig. 2 the differences between the GEM and net GEM dry deposition). To better assess the estimated dry deposition at this site, long-term litterfall, throughfall, and open area wet deposition (Graydon et al., 2008,
2009) were used to construct the dry deposition budget. It is noticed that the litterfall value $\left(8.6 \mu \mathrm{g} \mathrm{m}^{-2} \mathrm{yr}^{-1}\right.$; Fig. 3$)$ was at the low end of previously-published long-term estimates ( 8 to $12 \mu \mathrm{g} \mathrm{m}^{-2} \mathrm{yr}^{-1}$ ) that were probably more representative of the entire area. Also, the throughfall deposition (the difference between throughfall and open area wet deposition) was 0.15 to 0.85 times the litterfall deposition. Using the median litterfall and net throughfall deposition, one can obtain an annual dry deposition estimation (as the total of litterfall and net throughfall, and ignore soil deposition/emission) of $\sim 15 \mu \mathrm{g} \mathrm{m}^{-2} \mathrm{yr}^{-1}$. This is in very good agreement with the model-estimated dry deposition of $16.3 \mu \mathrm{g} \mathrm{m}^{-2} \mathrm{yr}^{-1}$ (Table 2).

The good agreement between the estimated deposition and the measured litterfall $\mathrm{Hg}$ suggests that the estimated dry deposition fluxes presented in this study are reasonable and conservative estimates. The speciated and total dry deposition numbers, in comparison with the litterfall deposition numbers, suggest that litterfall deposition should be mostly from the assimilation of GEM, consistent with one previous study (Rea et al., 2002).

The dry deposition amounts presented in this study are best-model estimates with large uncertainties (e.g., a factor of 2 for speciated and total dry depositon). As mentioned in Sect. 3.4, the GOM and PBM dry deposition are believed to be conservative estimates. To test the validity of the major 
Table 3. Estimated annual dry deposition $\left(\mu \mathrm{g} \mathrm{m}^{-2} \mathrm{yr}^{-1}\right)$ and measured annual wet deposition $\left(\mu \mathrm{g} \mathrm{m}^{-2} \mathrm{yr}^{-1}\right)$ at AMNeT/MDN collocated sites. Three-year average annual precipitation amount $(\mathrm{cm})$ is also shown.

\begin{tabular}{|c|c|c|c|c|c|c|c|c|}
\hline AMNet/MDN Site ID & Site Name & Site Category & $\mathrm{GOM}+\mathrm{PBM}$ & Net GEM & Total dry & Wet & Dry/wet & Precip \\
\hline MD08 & Piney Reservoir & Rural & 8.1 & 6.8 & 14.9 & 8.3 & 1.8 & 110 \\
\hline MD99 & Beltsville & Suburban & 1.6 & 9.0 & 10.6 & 9.7 & 1.1 & 112 \\
\hline NJ30 & New Brunswick & Urban & 0.9 & 23 & 23.9 & 8.6 & 2.8 & 126 \\
\hline NS01 & Kejimkujik National Park & Rural & 1.4 & 33 & 34.4 & 7.1 & 4.8 & 147 \\
\hline NY20 & Huntington Wildlife Forest & Rural & 0.4 & 4.8 & 5.2 & 6.1 & 0.9 & 113 \\
\hline $\mathrm{OH} 02$ & Athens Super Site & Rural & 3.4 & 9.9 & 13.3 & 8.4 & 1.6 & 96 \\
\hline OK99 & Stilwell & Rural & 0.7 & 9.3 & 10.0 & 12.6 & 0.8 & 135 \\
\hline UT97 & Salt Lake City & Urban & 5.0 & 10.0 & 15.0 & 6.0 & 2.5 & 36 \\
\hline VT99 & Underhill & Rural & 1.1 & 11.7 & 12.8 & 9.0 & 1.4 & 130 \\
\hline WV99 & Canaan Valley Institute & Rural & 4.0 & 8.2 & 12.2 & 9.3 & 1.3 & 125 \\
\hline
\end{tabular}

conclusions generated above (e.g., the relative contribution of GEM and GOM+PBM, the sources of $\mathrm{Hg}$ in litterfall), GOM and PBM dry deposition are adjusted by a factor of 2 and 4 (based on the potential uncertainties discussed in Sect. 3.4), respectively, which should represent their respective upper-end estimates. The increased GOM+PBM dry deposition for the six sites are listed in Table 2. With this adjustment, GEM dry deposition still dominated in the total dry deposition budget at four of the six sites; only at MD08 and WV99, is GOM+PBM as equally important as GEM in the total dry deposition budget. Thus, the conclusions generated above remain effective regardless of the potential uncertainties in the estimated speciated dry deposition.

The dominance of GEM in the litterfall $\mathrm{Hg}$ and in the total dry deposition raised the concern of its "bioavailability" once dry deposited. Organically-bound GEM temporarily stored in the leaves may eventually be released back into the atmosphere through biomass burning and other cycling processes (Friedli et al., 2009). However, Hg bound to organic matter can be methylated in riparian wetlands and similar conditions in the stream or stream corridor, and litterfall can be an important source of organic matter to streams (Benfield, 1997). Methylmercury, the bioavailable form of $\mathrm{Hg}$, was detected in all of the litterfall samples reported in Risch et al. (2012a). There is also indirect proof that some of the $\mathrm{Hg}$ in the foliage and in the litterfall is bioavailable. For example, songbirds and bats that feed on invertebrates have been shown to accumulate methylmercury concentrations at levels of concern. Methylmercury in the invertebrates is most likely due to their consumption of either forest canopy foliage or leaf litter on the forest floor, or the consumption of lower trophic level invertebrates that feed on foliage or leaf litter (Evers et al. 2012). Thus, the role of GEM dry deposition in ecosystem health needs more attention.

\subsection{Relative contribution of dry and wet deposition}

Within the domain of Fig. 4, there were ten collocated AMNeT/MDN sites that had data on both the dry deposition es- timates and the wet deposition measurements (Table 3). The wet deposition amounts during 2007-2009 at these sites did not reveal any urban-rural differences. Instead, variations in the wet deposition were mostly explained by the variations in precipitation amount. This is demonstrated by the high correlation between the wet deposition and the precipitation amount $\left(R^{2}=0.89, P=3.6 \times 10^{-5}\right)$. The lowest wet deposition was observed at an urban site (UT97) due to the extremely low precipitation amount. However, large precipitation amounts did not necessarily result in high wet deposition amounts if the ambient concentrations of GOM and PBM were extremely low, as was the case at NS01.

The GOM+PBM dry deposition amounts were similar to the wet deposition amounts at two of the sites (MD08 and UT97), but were only $6-43 \%$ of the wet deposition at the rest of the sites. However, the total dry deposition was more than the wet deposition at the majority of the sites, and the dry/wet ratio ranges from 0.8 to 4.8 at these locations. The relative contributions of dry and wet deposition to the total deposition budget were affected by the precipitation amount, the ambient concentration, the surface type, and the meteorological conditions.

Looking at the regional scale (Fig. 4), wet deposition for the areas covering the AMNet sites ranged from 6 to $9.0 \mu \mathrm{g} \mathrm{m}^{-2} \mathrm{yr}^{-1}$, and from 6 to $12 \mu \mathrm{g} \mathrm{m}^{-2} \mathrm{yr}^{-1}$ for the areas covering both the AMNet and litterfall sites (Fig. 4). If only $\mathrm{GOM}+\mathrm{PBM}$ was considered in the dry deposition budget, the wet deposition played a dominant role in the total (dry+wet) deposition budget. However, if the net GEM dry deposition was also considered, the total dry deposition became dominant over or equivalent to the wet deposition. This suggests that dry deposition was more important than wet deposition at a regional scale in central and eastern North America.

The importance of dry deposition in the total deposition budget was also supported by the comparison of the litterfall measurements with the wet deposition measurements (Risch et al., 2012a). It is thus concluded that the dry and wet depositional loadings are equally important on regional scales in eastern North America, similar to the conclusions of Miller 
et al. (2005). But the relative contribution of dry and wet deposition to the total deposition certainly depends on location, season, and meteorological conditions.

\section{Conclusions and recommendations}

Despite the potentially large uncertainties in the concentration measurements and in the calculated deposition velocities, the estimated dry deposition of GOM+PBM agrees with the limited surrogate-surface dry deposition measurements and the estimated annual total dry deposition $(\mathrm{GOM}+\mathrm{PBM}+$ net GEM) is in the same range as the annual litterfall $\mathrm{Hg}$ measurements. This provides some confidence on the estimated dry deposition. The results presented here suggest that GEM contributes much more than GOM+PBM to the total dry deposition at the majority of the sites studied here; the only exception is at the locations close to significant point sources where GEM and GOM+PBM contribute equally to the total dry deposition. This also implies that litterfall $\mathrm{Hg}$ is largely from the collection of GEM. Dry deposition has a similar value range to wet deposition, and thus needs to be quantified as accurately as possible.

Future work should focus on estimating net GEM dry deposition more accurately, especially considering its dominant role as a contributor to the total dry deposition. This will involve a better handling of the bi-directional exchange process, and a better understanding of GEM emission from natural surfaces. Recently, several research groups in the United States started measuring GEM gradients over forest canopies (10th ICMGP, Halifax, Canada, 23-29 July 2011). These measurements, together with modeling practices, should improve our understanding of net GEM dry deposition. It is recommended, wherever possible, to collect data that can be used to quantify GEM fluxes, both above the canopy and above the forest floor, so that the data can be used to develop and improve bi-directional exchange models for GEM.

\section{Supplementary material related to this article is available online at: http://www.atmos-chem-phys.net/12/ 4327/2012/acp-12-4327-2012-supplement.pdf.}

Acknowledgements. L. Zhang greatly appreciates I. Cheng for helpful discussion, A. Dastoor and A. Ryzhkov for providing GRAHM modeled GEM emission data, and AMNet site operators for their contribution in the collection of the speciated mercury ambient concentration data.

Edited by: J . H. Seinfeld

\section{References}

Amos, H. M., Jacob, D. J., Holmes, C. D., Fisher, J. A., Wang, Q., Yantosca, R. M., Corbitt, E. S., Galarneau, E., Rutter, A. P., Gustin, M. S., Steffen, A., Schauer, J. J., Graydon, J. A., Louis, V. L. St., Talbot, R. W., Edgerton, E. S., Zhang, Y., and Sunderland, E. M.: Gas-particle partitioning of atmospheric $\mathrm{Hg}$ (II) and its effect on global mercury deposition, Atmos. Chem. Phys., 12, 591-603, doi:10.5194/acp-12-591-2012, 2012.

Baker, K. R. and Bash, J. O.: Regional scale photochemical model evaluation of total mercury wet deposition and speciated ambient mercury, Atmos. Environ., 49, 151-162, 2012.

Bash, J. O., Bresnahan, P. A., and Miller, D. R.: Dynamic surface interface exchanges of mercury: A review and compartmentalized modeling framework, J.Appl. Meteorol. Climatol., 46, 16061618, 2007.

Bash, J. O.: Description and initial simulation of a dynamic bidirectional air surface exchange model for mercury in Community Multiscale Air Quality (CMAQ) model, J. Geophys. Res., 115, D06305, doi:10.1029/2009JD012834, 2010.

Benfield, E. F.: Comparison of Litterfall Input to Streams, J. N. Am. Benthol. Soc., 16, 104-108, 1997.

Brook, J. R., Zhang, L., Franco, D., and Padro J.: Description and evaluation of a model of deposition velocities for routine estimates of air pollutant dry deposition over North America. Part I. Model development, Atmos. Environ., 33, 5037-5052, 1999.

Bullock Jr., O. R. and Brehme, K. A.: Atmospheric mercury simulation using the CMAQ model: Formulation description and analysis of wet deposition results. Atmos. Environ., 36, 2135-2146, 2002.

Bullock, O. R., Atkinson, D., and Braverman, T.: The North American mercury model intercomparison study (NAMMIS): Study description and model-to-model comparisons, J. Geophys. Res., 113, D17310, doi:10.1029/2008JD009803, 2008.

Castro, M. S., Moore, C., Sherwell, J., and Brooks, S. B.: Dry Deposition of Gaseous Oxidized Mercury in Western Maryland, Sci. Total Environ., 417/418, 232-240, 2012.

Cheng, I., Zhang, L., Blanchard, P., Graydon, J. A., and Louis, V. L. St.: Source-receptor relationships for speciated atmospheric mercury at the remote Experimental Lakes Area, northwestern Ontario, Canada, Atmos. Chem. Phys., 12, 1903-1922, doi:10.5194/acp-12-1903-2012, 2012.

Cobbett, F. D. and Van Heyst, B. J.: Measurements of GEM fluxes and atmospheric mercury concentrations (GEM, RGM and Hgp) from an agricultural field amended with biosolids in Southern Ont., Canada (October 2004-November 2004), Atmos. Environ., 41, 2270-2282, 2007.

Dastoor, A. P. and Larocque, Y.: Global circulation of atmospheric mercury: a modeling study, Atmos. Environ., 38, 147-161, 2004.

Dastoor, A. P., Davignon, D., Theys, N., Van Roozendael, M., Steffen, A., and Ariya, P. A.: Modeling dynamic exchange of gaseous elemental mercury at polar sunrise, Environ. Sci. Technol., 42, 5183-5188, 2008.

Demers, J. D., Driscoll, C. T., Fahey, T. J., and Yavitt, J. B.: Mercury cycling in litter and soil in different forest types in the Adirondack region, New York, USA, Ecol. Appl., 17, 1341-1351, 2007.

Engle, M. A., Tate, M. T., Krabbenhoft, D. P., Schauer, J. J., Kolker, A., Shanley, J. B., and Bothner, M. H.: Comparison of atmospheric mercury speciation and deposition at nine sites across central and eastern North America, J. Geophys. Res.- 
Atmospheres, 115, D18306, doi:10.1029/2010JD014064, 2010.

Evers, D. C., Jackson, A. K., Tear, T. H., and Osborne, C. E.: Hidden Risk: Mercury in Terrestrial Ecosystems of the Northeast, Biodiversity Research Institute, Gorham, Maine, 33 pp., 2012.

Flechard, C. R., Nemitz, E., Smith, R. I., Fowler, D., Vermeulen, A. T., Bleeker, A., Erisman, J. W., Simpson, D., Zhang, L., Tang, Y. S., and Sutton, M. A.: Dry deposition of reactive nitrogen to European ecosystems: a comparison of inferential models across the NitroEurope network, Atmos. Chem. Phys., 11, 2703-2728, doi:10.5194/acp-11-2703-2011, 2011.

Friedli, H. R., Arellano, A. F., Cinnirella, S., and Pirrone, N.: Initial estimates of mercury emissions to the atmosphere from global biomass burning, Environ. Sci. Technol., 43, 3507-3513, 2009.

Gbor, P. K., Wen, D., Meng, F., Yang, F., and Sloan, J. J.: Modeling of mercury emission, transport and deposition in North America, Atmos. Environ., 41, 1135-1149, 2007.

Graydon, J. A., St. Louis, V. L., Hintelmann, H., Lindberg, S. E., Sandilands, K. A., Rudd, J. W. M., Kelly, C. A., Hall, B. D., and Mowat, L. D.: Long-term wet and dry deposition of total and methyl mercury in the remote boreal ecoregion of Canada, Environ. Sci. Technol., 42, 8345-8351, 2008.

Graydon, J. A., St. Louis, V. L., Hintelmann, H., Lindberg, S. E., Sandilands, K. A., Rudd, J. W. M., Kelly, C. A., Tate, M. T., Krabbenhoft, D. P., Lehnherr, I.: Investigation of uptake and retention of atmospheric $\mathrm{Hg}$ (II) by boreal forest plants using stable Hg isotopes, Environ. Sci. Technol., 43, 4960-4966, 2009.

Gustin, M. S. and Jaffe, D.: Reducing the Uncertainty in Measurement and Understanding of Mercury in the Atmosphere, Environ. Sci. Technol., 44, 2222-2227, 2010.

Gustin, M. S., Lindberg, S. E., and Weisberg, P. J.: An update on the natural sources and sinks of atmospheric mercury, Appl. Geochem., 23, 482-493, 2008.

Huang, J., Choi, H.-D., Hopke, P. K., and Holsen, T. M.: Ambient Mercury Sources in Rochester, NY: Results from Principle Components Analysis (PCA) of Mercury Monitoring Network Data, Environ. Sci. Technol., 44, 8441-8445, 2010.

Huang, J., Choi, H.-D., Landis, M. S., and Holsen, T. M.: An application of modified passive samplers for understanding of atmospheric mercury concentration and dry deposition spatial distribution, Atmos. Environ., submitted, 2012.

Keeler, G. J. and Dvonch, T. J. Atmospheric Mercury: A Decade of Observations in the Great Lakes. Dynamics of Mercury Pollution on Regional and Global Scales: Atmospheric Processes and Human Exposures Around the World, XII, 611-636, 2005.

Kos, G., Ryzhkov, A., and Dastoor, A.: Analysis of uncertainties in measurements and model for oxidised and particle-bound mercury. Presented in the 10th International Conference on Mercury as a Global Pollutant, 24-29 July, 2011, Halifax, Nova Scotia, Canada, 2011.

Landis, M. S. and Keeler, G. J.: Atmospheric Mercury Deposition to Lake Michigan during the Lake Michigan Mass Balance Study, Environ. Sci. Technol., 36, 4518-4524, 2002.

Landis, M. S., Stevens, R. K., Schaedlich, F., and Prestbo, E. M.: Development and characterization of an annular denuder methodology for the measurement of divalent inorganic reactive gaseous mercury in ambient air, Environ. Sci. Technol., 36, 3000-3009, 2002.

Lin, C. J., Pongprueksa, P., Lindberg, S. E., Pehkonen, S. O., Byun, D., and Jang, C.: Scientific uncertainties in atmospheric mercury models i: Model science evaluation. Atmos. Environ., 40, 2911 2928, 2006.

Lin, C. J., Pongprueks, P., Bullock Jr., O. R., Lindberg, S. E., Pehkonen, S. O., Jang, C., Braverman, T., and Ho, T. C.: Scientific uncertainties in atmospheric mercury models ii: Sensitivity analysis in the conus domain. Atmos. Environ., 41, 6544-6560, 2007.

Lindberg, S., Bullock Jr., O. R.,, Ebinghaus, R., Engstrom, D., Feng , X., Fitzgerald, W., Pirrone, N., and Seigneur, C.: A synthesis of progress and uncertainties in attributing the sources of mercury in deposition, Ambio, 36, 19-32, 2007.

Lindberg, S. E., Hanson, P. J., Meyers, T. P., and Kim, K.-H.: Air/surface exchange of mercury vapour over forests - The need for a reassessment of continental biogenic emissions, Atmos. Environ., 32, 895-908, 1998.

Lombard, M. A. S., Bryce, J. G., Mao, H., and Talbot, R.: Mercury deposition in Southern New Hampshire, 2006-2009, Atmos. Chem. Phys., 11, 7657-7668, doi:10.5194/acp-11-76572011, 2011.

Lyman, S. N., Gustin, M. S., Prestbo, E. M., and Marsik, F. J.: Estimation of dry deposition of atmospheric mercury in Nevada by Direct and Indirect Methods, Environ. Sci. Technol., 41, 19701976, 2007.

Lyman, S. N., Gustin, M. S., and Prestbo, E. M.: A passive sampler for ambient gaseous oxidized mercury concentrations, Atmos. Environ., 44, 246-252, 2010a.

Lyman, S. N., Jaffe, D. A., and Gustin, M. S.: Release of mercury halides from $\mathrm{KCl}$ denuders in the presence of ozone, Atmos. Chem. Phys., 10, 8197-8204, doi:10.5194/acp-10-81972010, 2010b.

Mao, H. and Talbot, R.: Speciated mercury at marine, coastal, and inland sites in New England -Part 1: Temporal variability, Atmos. Chem. Phys. Discuss., 11, 32301-32336, doi:10.5194/acpd-11-32301-2011, 2011.

Marsik, F. J., Keeler, G. J., and Landis, M. S.: The dry deposition of speciated mercury to the Florida Everglades: measurements and modeling, Atmos. Environ., 41, 136-149, 2007.

Mason, R. P. and Sheu, G.-R.: The role of the ocean in the global mercury cycle. Global Biogeochem. Cy.,16, 1093, 2002.

Mason, R. P., Abbott, M. L., Bodaly, R. A., Bullock, O. R. Jr., Driscoll, C. T., Evers, D., Lindberg, S. E., Murray, M., and Swain, E. B.: Monitoring the response to changing mercury deposition, Environ. Sci. Technol., 39, 14A-22A, 2005.

Miller, E. K., Vanarsdale, A., Keeler, G. J., Chalmers, A., Poissant, L., Kamman, N. C., and Brulotte, R.: Estimation and mapping of wet and dry mercury deposition across northeastern North America, Ecotoxicol., 14, 53-70, 2005.

National Atmospheric Deposition Program (NADP): AMNet Standard Operating Procedure Site Report A: Each Visit/Weekly Maintenance. Illinois State Water Survey, Champaign IL, http: //nadp.isws.illinois.edu/amn/docs/, last access: November 2011, 2011a.

National Atmospheric Deposition Program (NADP): AMNet Standard Operating Procedure Site Report B: Glassware Changeout/Monthly Maintenance. Illinois State Water Survey, Champaign IL, http://nadp.isws.illinois.edu/amn/docs/, last access: November 2011, 2011b.

National Atmospheric Deposition Program (NADP): AMNet Standard Operating Procedure Site Report C: Quarterly Maintenance. Illinois State Water Survey, Champaign IL, http://nadp.isws. 
illinois.edu/amn/docs/, last access: November 2011, 2011c.

National Atmospheric Deposition Program (NADP):AMNet Standard Operating Procedure Site Report D: Annual/As Needed Maintenance. Illinois State Water Survey, Champaign IL, http: //nadp.isws.illinois.edu/amn/docs/, last access: November 2011, 2011d.

National Atmospheric Deposition Program (NADP): Atmospheric Mercury Network Data Management Manual, Version 1.4, Illinois State Water Survey, Champaign IL, http://nadp.isws.illinois. edu/amn/docs/, last access: November 2011, 2011e.

Pongprueksa, P., Lin, C. J., Lindberg, S. E., Jang, C., Braverman, T., Bullock Jr., O. R., Ho, T. C., and Chu, H. W.: Scientific uncertainties in atmospheric mercury models iii: Boundary and initial conditions, model grid resolution, and hg(ii) reduction mechanism, Atmos. Environ., 42, 1828-1845, 2008.

Rea, A. W., Lindberg, S. E., Scherbatskoy, T., Keeler, G. J.: Mercury accumulation in foliage over time in two northern mixed hardwood forests, Water Air Soil Pollut., 133, 49-67, 2002.

Prestbo, E. M. and Gay, D. A.: Wet deposition of mercury in the U.S. and Canada, 1996-2005: Results and analysis of the NADP mercury deposition network (MDN), Atmos. Environ., 43, 42234233, 2009.

Risch, M. R., DeWild, J. F., Krabbenhoft, D. P., Kolka, R. K., and Zhang, L.: Mercury in Litterfall at Selected National Atmospheric Deposition Program Mercury Deposition Network Sites in the Eastern United States, 2007-2009, Environ. Pollut., 161, 284-290, 2012a.

Risch, M., Gay, D., Fowler, K., Keeler, G., Blanchard, P., Backus, S., Barres, J., and Dvonch, T.,: Spatial Patterns and Statistical Trends in Mercury Concentrations, Precipitation, and Mercury Wet Deposition in the North American Great Lakes Region, 2002-2008. Environ. Pollut., 161, 261-271, 2012b.

Sakata, M. and Asakura, K.: Evaluating relative contribution of atmospheric mercury species to mercury dry deposition in Japan, Water Air Soil Poll., 193, 51-63, 2008.

Schroeder, W. H., Munthe, J., and Lindqvist, O.: Cycling of mercury between water, air, and soil compartments of the environment, Water Air Soil Pollut., 48, 337-347, 1989.

Selin, N. E., Jacob, D. J., Park, R. J., Yantosca, R. M., Strode, S., Jaegle, L., and Jaffe, D.: Chemical cycling and deposition of atmospheric mercury: global constraints from observations, J. Geophys. Res., 112, D02308, doi:10.1029/2006JD007450, 2007.

Shetty, S. K., Lin, C. J., Streets, D. G., and Jang, C.: Model estimate of mercury emission from natural sources in East Asia, Atmos. Environ., 42, 8674-8685, 2008.
Skov, H., Brooks, S. B., Goodsite, M. E., Lindberg, S. E., Meyers, T. P., Landis, M. S., Larsen, M. R. B., and Christensen, J.: Fluxes of reactive gaseous mercury measured with a newly developed method using relaxed eddy accumulation, Atmos. Environ., 40, 5452-5463, 2006.

Sprovieri, F., Pirrone, N., Ebinghaus, R., Kock, H., and Dommergue, A.: A review of worldwide atmospheric mercury measurements, Atmos. Chem. Phys., 10, 8245-8265, doi:10.5194/acp10-8245-2010, 2010.

Vanarsdale, A., Weiss, J., Keeler, G., Miller, E., Boulet, G., Brulotte, R., and Poissant, L.: Patterns of mercury deposition and concentration in northeastern North America (1996-2002). Ecotoxicology, 14, 37-52, 2005.

Wesely, M. L.: Parameterization of surface resistances to gaseous dry deposition in regional-scale numerical models, Atmos. Environ., 23, 1293-1304, 1989.

Xu, X., Yang, X., Miller, D. R., Helble, J. J., and Carley, R. J.: Formulation of bi-directional atmosphere-surface exchanges of elemental mercury, Atmos. Environ., 33, 4345-4355, 1999.

Zhang, L., Gong, S., Padro, J., and Barrie, L. A.: A size-segregated particle dry deposition scheme for an atmospheric aerosol module, Atmos. Environ., 35, 549-560, 2001.

Zhang, L., Moran, M., Makar, P. Brook, J., and Gong, S.: Modelling Gaseous Dry Deposition in AURAMS - A Unified Regional Airquality Modelling System, Atmos. Environ., 36, 537-560, 2002.

Zhang, L., Brook, J. R., and Vet, R.: A revised parameterization for gaseous dry deposition in air-quality models, Atmos. Chem. Phys., 3, 2067-2082, doi:10.5194/acp-3-2067-2003, 2003.

Zhang, L., Wright, L. P., and Blanchard, P.: A review of current knowledge concerning dry deposition of atmospheric mercury, Atmos. Environ., 5853-5864, 2009.

Zhang, L., Blanchard, P., Johnson, D., Dastoor, A., Ryzhkov, A., Lin, C.-J., Vijayaraghavan, K., Gay, D., Holsen, T. M., Huang, J., Graydon, J.A., St. Louis, V. L., Castro, M. S., Miller, E. K., Marsik, F., Lu, J., Poissant, L., Pilote, M. and Zhang, K. M.: Assessment of modeled mercury deposition over the Great Lakes region, Environ. Pollut., 161, 272-283, 2012a.

Zhang, L., Fang, G. C., Liu, C. K., Huang, Y. L., Huang, J. H., and Huang, C. S.: Dry deposition fluxes and deposition velocities of seven trace metal species at five sites in central Taiwan - A summary of surrogate-surface measurements and a comparison with model estimation, Atmos. Chem. Phys., 12, 3405-3417, doi:10.5194/acp-12-3405-2012, $2012 \mathrm{~b}$. 